\title{
Synergy in the Development of Modern Forms of Life Activity
}

\author{
Evgeny Bryndin \\ Research Department, Research Center "Natural Informatics", Novosibirsk, Russia
}

Email address:

bryndin15@yandex.ru

To cite this article:

Evgeny Bryndin. Synergy in the Development of Modern Forms of Life Activity. International Journal of Science and Qualitative Analysis. Vol. 7, No. 1, 2021, pp. 1-6. doi: 10.11648/j.ijsqa.20210701.11

Received: March 10, 2021; Accepted: March 19, 2021; Published: March 26, 2021

\begin{abstract}
The Davos Forum of 2021 highlighted the most important trends that in the coming years will determine the "Great Reset" - the sustainable recovery of the world economy after the pandemic and the rethinking of world politics. For a reboot, the author offers a synergistic approach to a reboot. The article discusses the synergy of various forms of social development. First, the spiritual and moral synergy of the formation of a culture of peace of transnational communication is considered. Secondly, the scientific and educational synergy of training creative personnel for creative activities is described. Thirdly, the financial and organizational synergy of economic environment development is briefly considered. Fourth, the project-innovative synergy of integration processes in innovation activities for the development of scientific, technical, technological, production, investment and personnel potential is discussed, as well as on the growth of labor productivity, improvement of structures and competitive ability of industries. Fifthly, industrial and technological synergy between technology and industry is proposed for the effective adjustment of the labor market and the formation of effective principles for the work of our economic system. Sixth, the health environmental synergy health saving nation and ecological development of living spaces is discussed. The Davos Forum of 2021 highlighted the most important trends that in the coming years will determine the "Great Reset" - the sustainable recovery of the world economy after the pandemic and the rethinking of world politics. For a reboot, the author offers a synergistic approach to a reboot. The article discusses the synergy of various forms of social development. First, the spiritual and moral synergy of the formation of a culture of peace of transnational communication is considered. Secondly, the scientific and educational synergy of training creative personnel for creative activities is described. Thirdly, the financial and organizational synergy of economic environment development is briefly considered. Fourth, the project-innovative synergy of integration processes in innovation activities for the development of scientific, technical, technological, production, investment and personnel potential is discussed, as well as on the growth of labor productivity, improvement of structures and competitive ability of industries. Fifthly, industrial and technological synergy between technology and industry is proposed for the effective adjustment of the labor market and the formation of effective principles for the work of our economic system. Sixth, the health environmental synergy health saving nation and ecological development of living spaces is discussed.
\end{abstract}

Keywords: Synergy, Spiritual, Scientific, Educational, Organizational, Innovative, Technological, Health

\section{Introduction}

One of the most important challenges of our time is ensuring timely technological development. The need to create robotics, artificial intelligence, electronic commerce, the formation of its own network platforms, the transition of enterprises to environmental technologies is outlined. This requires synergy between education, science, industry and the intensification of innovative research.
The main vector of modern global competition lies in the field of dynamically changing advantages based on scientific and technological achievements and innovations. The experience of the most developed countries shows that competitiveness is ensured by a number of institutional conditions, the main of which is the formation and operation of a national innovation system. 
Innovative and technological cooperation and partnership play an increasing role. Technological and innovative cooperation arises when several different companies decide to create a common enterprise in order to implement a joint project, the main goal of which is to create innovative products.

The main form of integration is cooperation between universities, research centers and industrial enterprises. A prerequisite for successful integration in the innovation sphere is the development of processes of close interaction in the economy, science and education. Wide professional cooperation and development of processes of innovative and technological interaction creates synergy of development in all spheres of life.

\section{Spiritual and Moral Synergy of Transnational Communication}

Spiritual and moral synergy is a great goal to which the world community aspires. At the same time, this is a learning process, it is a global school in which people learn to live together, learn peace, mutual understanding, solidarity. The path to spiritual and moral synergy lies through dialogue and the culture of the world of peoples, states, religious denominations. Dialogue and its able organization should also be learned. The process of building a culture of peace and the process of initiating and improving dialogue between the family, peoples, religious denominations and States are dialectically interrelated processes. Practically, the culture of peace is formed by human qualities based on spiritual and moral values. It neutralizes actions that lead to aggravation of contradictions and finding opportunities for their smoothing, settlement. Dialogue is one of the most reliable means of solving this problem. The culture of peace is aimed at building a dialogue that creates opportunities for citizens to cooperate with different worldviews, which contributes to increasing the space of justice and reducing inequality, promotes sustainable spiritual and moral development, as well as the formation of ideals of understanding, peacefulness and solidarity among all. The culture of peace includes values, attitudes and moral behaviour that shape social interaction and cooperation on the basis of the principles of unity and equality of freedom, justice and peace. And on the basis of the acquisition of rights to participate in the development of the family and society in the performance of duties.

Spiritual and moral synergy based on the culture of peace tries to solve the problems of modern life and extremely complex relations in modern society, considering the world as holistically as possible. The driving force of the association is human capital, seeking the sphere of application in the development of various forms of social organization. A society that creates new knowledge and technologies in conjunction with the culture of the world will develop only based on the spiritual and moral synergy of people $[1,2]$.

\section{Scientific and Educational Synergy of Development}

Combining educational and scientific activities, their synergy is a factor and a real means of improving the efficiency and competitiveness of an innovative economy. Synergy between education and science is a prerequisite for the development of research and innovation.

Synergy in the integration of science and education gives an accelerated educational effect in the training of highly qualified personnel. The accelerated process of training highly qualified personnel is being implemented through the integration of higher education with advanced research fundamental science. Education and science, especially in their synergistic synthesis, are increasingly becoming the engine of technological progress, without which socioeconomic progress is unthinkable in our time. High-quality training, based on an alliance with scientific activities, is a policy priority in all developed countries of the world, as well as a necessary component of the institutional structure of an innovative economy.

The reproduction of highly qualified personnel meeting the requirements of an innovative economy has a high priority. Large corporations should invest sufficiently in research and development in the field of high technology, training specialists of appropriate quantity and quality, and form a system of public-private partnership in higher education. The creation of large educational complexes based on the joint activities of the university and the production sector is one of the most important areas of intersectoral cooperation for the development of high-tech industry.

The future is for creative personalities capable of constant creative self-realization. Albert Einstein said, "imagination is more important than knowledge." Development of a person's creative abilities, expansion of opportunities of individual innovation activity, mobilization of an employee's potential for realization of own ideas and developments provides creative education [3-5]. The peculiarity of creative education is that it is aimed at developing a constant need for creation, finding a new one, in accumulating intellectual potential and using it in practice.

A new quality of work appears - creative activity as a function of the self-realization of a holistic person, a creator. Deep fundamental training, characteristic of creative education, gives a synergistic effect, promotes continuous learning, allows you to predict and evaluate development trends. Creative education expands the perception of problems and options for solving them, stimulates a creative approach to solving them. But the main thing is to realize the idea of the need and possibility of training creative activities. Now we need workers with a search mentality, creative intuition, a clear vision of what this or that new technology should lead to. This requires the development of scientific, educational and financial and organizational synergies. 


\section{Financial and Organizational Synergy}

Financial and organizational synergy plays a significant role in the development of various forms of social organization. The role of the social environment is played by a set of objects and entities between which production, economic and other relations are carried out. Money and its volume, expressed in some equivalent, is the financial size of the entities. The amount of money owned by an entity or corporation is its financial volume. In the financial system, there is a constant turnover of the money supply. The period of complete circulation of the money supply of a particular subject determines the frequency of circulation. And its speed is the ratio of the money supply to the circulation period.

The whole set of subjects has a financial dispersion ratio of the economic environment. Each subject of economic activity successfully in this field corresponds to a certain connection between its volume and the frequency of turnover of funds. This relationship can be experimentally determined. If a new participant in the economic structure emerges, his activities will be successful if his capital and the estimated frequency of his turnover correspond to the dispersion ratio of the economic environment in which he intends to operate. This condition is necessary but not sufficient for success. It is also necessary that partners have close values of capital and its turnover rates. When companies with different amounts of capital cooperate, then in a larger company there should be a division that is close in terms of capital with a smaller of the companies, interacting with it. Company management, which provides these financial ratios, creates conditions for financial and organizational synergy in the development of the economic environment based on innovative design.

\section{Design and Innovation Synergy of Development}

Today, the building of a competitive society and the rise of wealth are largely associated with innovative research and development, since the global economy is dominated by the trend of increasing the innovative capacity of GDP and an innovative scenario for its development has been established.

Synergy of innovation project management has a summing effect of interaction of two or more factors, characterized by the fact that their effect significantly exceeds the effect of each individual component in the form of their simple sum.

An innovation project is a form of targeted innovation management, the process of innovation implementation. As a form of targeted innovation management, an innovation project is a complex system of mutually agreed and interconnected events on resources, timelines and performers aimed at achieving specific goals (goals) in the priority areas of science and technology development. As a process of innovation, it is a set of scientific, technological, production, organizational, financial and commercial events carried out in a certain sequence, leading to innovation. At the same time, an innovative project is a set of technical, organizational, planned and settlement-financial documents necessary for the implementation of the project goals.

Implementation of the plan of the innovative project is provided by the project participants. Depending on the type of project, up to several dozen organizations can take part in its implementation. Each of them has its own functions, the degree of participation in the project and the measure of responsibility for its fate. All these organizations, depending on the functions they perform, it is more advisable to combine into group categories of project participants for a synergistic effect. The project team becomes a specific organizational structure, led by the project manager in order to effectively achieve the goals of innovation.

The sources of innovation synergy are integration processes. Synergy of integration processes in innovation activity contributes to development of its combined potential - scientific and technical, technological, production, investment and personnel, increase of labor productivity, improvement of structures and competitive ability of production. Ivanova I., Strand Ø., Leydesdorff L. show the development of aggregate capacity at the regional level of Norway in its work [6].

\section{Industrial and Technological Synergy of Development}

The synergy of industry and technology has led to the 4.0 industry and increased employee productivity. In the era of the digital economy, technology itself turns into workers, greatly blurring the boundary between labor and capital opportunities. The driving factor for all processes is the expansion of computer technology. The approach to doing business under the influence of technology development has changed, in particular, the need for hiring employees to perform everyday routine tasks, which have always been an essential part of the activities of any company, has sharply decreased. Algorithms and technologies are being developed that do routine work, or a significant part of it. There is an increasing penetration of the big data phenomenon into our lives. Organizations collect an unimaginable amount of information on almost all aspects of activities, this data includes details of a huge set of skills and operations. Computers learn to learn new skills easily and quickly, especially when they have access to a large amount of data for training.

Robots have become indispensable in almost all industries - from automotive to semiconductor manufacturing. At the Tesla electric vehicle manufacturer's plant in Fremont, California, 160 universal industrial robots assemble approximately 400 cars a week. As soon as the chassis of the new car is at the next point in the assembly line, several manipulators descend to it at once and begin to work in close cooperation with each other. Robots are able to independently change the tools installed on the manipulators, which allows you to perform various tasks. The same robot first mounts the seats, and then, changing the tools, applies 
the adhesive composition and installs the windshield. Given the ability of universal robots to work without interruptions and rapid training in new types of work, their attractiveness as an alternative to humans is growing.

A factor in future automation is the rapid growth of the selfservice sector, that is, intelligent vending machines and kiosks. The scope of vending machines has not long been limited to the sale of soda, chocolate bars and creepy soluble coffee: in many airports and expensive hotels, sophisticated vending machines are now being installed that sell consumer electronics, including iPod, iPad and other Apple devices. AVT Inc., a leading manufacturer of vending machines, says it can design custommade self-service systems for almost any product.

The capture of the market by online stores has led to the movement of employees from familiar stores to warehouses and logistics centers. The functions of a warehouse employee are much easier to automate than the responsibilities of a store employee. When trading companies are engaged in the full modernization of outlets, turning them into huge vending machines. Such a store will consist of an automated warehouse with an adjacent trading room, in which customers will be able to familiarize themselves with product samples and make an order. After receiving the order, the goods will be transferred directly to customers or even delivered using robots to their machines.

Synergy between technology and industry leads to a fundamental restructuring of the labor market and to effective principles of the financial system. Synergistic influence of innovative technologies on the work of firms is considered in the works [7-8]. Its basis is the financial stability of the healthy life of each person. The basis of financial stability of healthy life activity of each person is uniformity [9]. Now your excess to fill their deficiency; and after their excess to fill your disadvantage, so that there was uniformity, as it is written: who collected a lot, did not have excess; and few had a shortage (2 Corinthians 8: 12-15).

The main parameter of the financial balance of the population of the territories should be the starting norm of healthy life for all participants in economic spheres and social programs. The starting norm of healthy life allows us to ensure financial stability globally. For this, the amount of money in the economy of the territories should always be enough for the production and consumption of products, goods and services of healthy living activities by the population living on it. It is also necessary to ensure equal regulation of pricing, taking into account the demographic situation and changing demand and supply in the market.

Financial balances of a uniform economy should provide all participants in economic activities and social programs with finance for healthy living.

Let PC - product cost,

QPG - quantity of production goods,

MCG - market cost of the goods,

$\mathrm{NP}$ - number of participants in products,
NPP - number of producers products,

D - demand,

MP - market profit,

APF - assignments from profit in funds;

AP - appropriated profit,

SENHL - social and economic norm of healthy life,

LP - labor productivity.

Then

QPG x $(\mathrm{MCG}-\mathrm{C \Pi})=\mathrm{MP}$;

$\mathrm{AP}=\mathrm{MP}-\mathrm{APF}$;

$\mathrm{AP} / \mathrm{SENHL}=\mathrm{NP}$;

$\mathrm{QPG} / \mathrm{NPP}=\mathrm{LP}$.

At $100 \%$ demand for healthy life $\mathrm{D} \geq \mathrm{QPG}$, AP provides all its participants with the finance for healthy life.

Maintenance of the population with starting social and economic norm of healthy life is carried out by uniform regulation of pricing from a position of realization of the future demand for healthy ability to live.

Let $\{\mathrm{Xi}\}$ - set of the goods in the market, where $\mathrm{i}=1 \ldots \ldots . . \mathrm{n}$;

$\mathrm{Xi}$ - quantity of $\mathrm{i}$ goods;

$\mathrm{Ci}$ - cost of resources on manufacture $\mathrm{Xi}$ of the goods;

$\mathrm{Ki}$ - quantity of employees participating in manufacture and realization $\mathrm{Xi}$ of the goods;

NHL - norm of healthy ability to live;

$\mathrm{WFi}$ - a wages fund of employees participating in manufacture and realization $\mathrm{Xi}$ of the goods;

where $\mathrm{WFi} \geq(\mathrm{Ki} \times \mathrm{NHL})$ for all $\mathrm{i}$;

$\mathrm{Pi}$ - profit on realization $\mathrm{Xi}$ of the goods in the market, where $\mathrm{Pi}>\mathrm{WFi}$ for all $\mathrm{i}$;

PGMi - the price of $\mathrm{i}$ goods in the market;

$\mathrm{K}$ - quantity of the population;

$\mathrm{P}$ - cumulative market profit, where $\mathrm{P}=\Sigma \mathrm{Pi}$;

If $\mathrm{PGMi}>(\mathrm{WFi}+\mathrm{Ci})$ : $\mathrm{Ki}$ for all $\mathrm{i}$; that $\mathrm{P}: \mathrm{K} \geq \mathrm{NHL}$; (1)

If $\mathrm{WFi}<(\mathrm{Ki} \times \mathrm{NHL})$ increases PGMi, that PGMi $>(\mathrm{WFi}+$ Ci): Ki.

If financial balances of all levels provide condition 1 , then they support society with the starting norm of healthy life.

A correct financial balance between urban and rural populations will maintain a market balance between supply and demand.

Macroeconomic equilibrium is achieved as a result of the joint actions of the state and business, factors of production, demand and supply, in which the way of using production resources to create various products, goods and services and their distribution among citizens of the population are balanced [10]. Dynamic equilibrium is achieved by regulating pricing and cross-industry balance with equilibrium prices.

Socio-economic stabilization of global well-being is carried out by ensuring purchasing power, solvent demand, price balancing, balanced state budgets and project financing and management (Figure 1). 


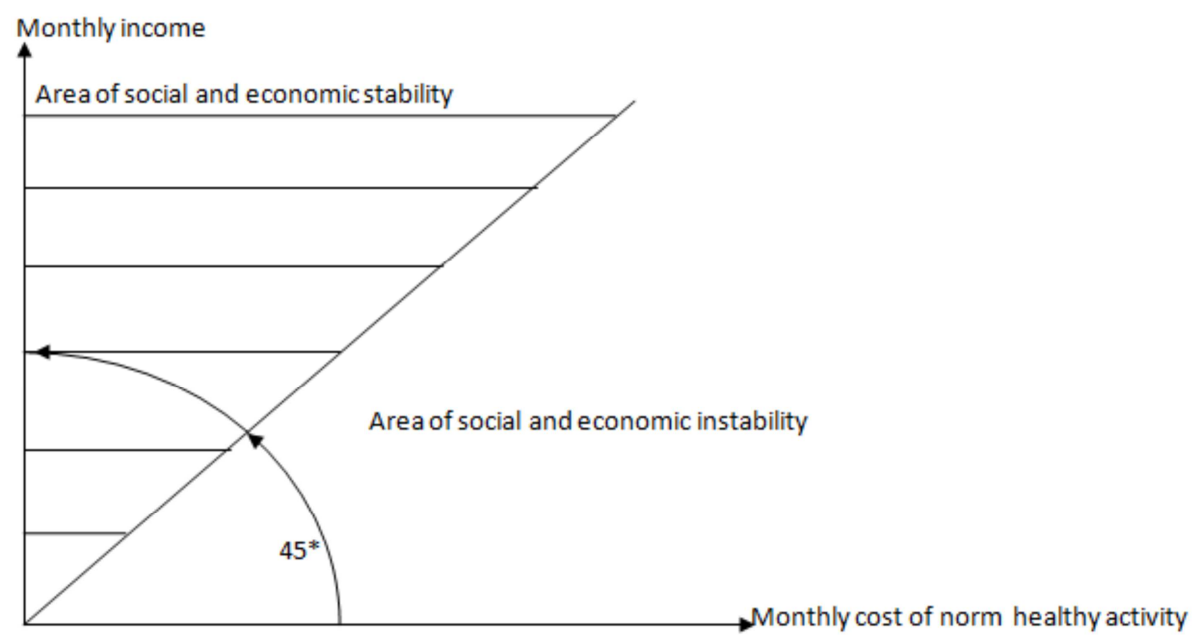

Figure 1. Socio-economic stabilization of global well-being.

By investing in environmental projects, health support projects and projects to improve the quality of life, environmental synergy is realized.

\section{Health Environmental Synergy}

Health and ecology are the basis of the quality of life on Earth. Synergy between ecology and health is achieved by implementing environmental and health conservation programs. The environmental program "Clean air, clean water, clean food, clean energy, clean cities and villages, clean Nature" should be focused on the formation of a IVF, firstly, on improving the quality of environmental expertise and the responsibility of small, medium and large businesses for air pollution, water, food, territory and Nature. Secondly, the responsibility of environmental services and authorities for the ecological state of air, drinking water, the territory of the city and the village. Thirdly, to develop and support environmental projects and events for environmental control, accounting and conservation. Fourth, the development and implementation of an automated system for recording and controlling the purity of air, water, food, energy, cities and villages, the environment of Nature. Information from the automated control system, which comes to the state and public environmental regulatory bodies, will quickly respond to negative phenomena. Fifth, the introduction of the process of construction and acquisition of housing on the basis of shared participation. The implementation of this program will contribute to the prompt resolution of all issues aimed at restoring the ecology and using rechargeable sources of energy, and most importantly, the transformation of the land into a reserve, where people will live according to environmental reserves that do not violate natural nature.

The hierarchy of life in the eco world is built along a chain: the eco state, the eco city, the eco home. In the eco state, eco cities and eco houses, eco life, eco production and eco communication are formed. The cycles of production, domestic and social processes do not disturb the harmony of natural nature at the material, energy and spiritual levels. Cycles are carried out by society without interfering in the natural course of nature, in its natural content, in the world around it, neither domestic, nor industrial, nor social processes. Society and man live in an eco-world in harmony based on environmental norms of life, communication and production. A person from birth in the family is included in the eco of life. Environmental thinking, eco-attitude, ecobehavior lead a person and society to a healthy lifestyle in the home, city, country and world. The ecological world is developing on the basis of scientific achievements leading to waste-free technologies that do not disturb the balance of the natural content of the environment of society, animal and plant world and life on Earth [11].

The nation's health saving program is formed on the basis of a healthy lifestyle. In order to bring the population Russia to a healthy lifestyle, it is necessary to develop health-saving medicine and a health-saving health system. Health saving medicine will train specialists in tuning the body for a healthy state and a healthy lifestyle. The health saving health system will periodically diagnose the population, teach the population how to tune the body to a healthy state and healthy lifestyle, help through health prevention centers to tune the body to a healthy state and switch to a healthy lifestyle. A healthy lifestyle ensures a person's health all his life [12-14]. A healthy population will form a healthy society. For this, the norm of a healthy person should become the starting socio-economic norm. The norm of a healthy person will be ensured by environmental health saving economy with recoverable resources. A health-saving health system will be able to realize the economic cycle of replenishing and preserving a healthy human resource. Health saving medicine and health saving health system will transfer the population of Russia to a healthy lifestyle. The transition of the population to a healthy lifestyle is carried out in three stages. Firstly, the development of wellness abilities at the spiritual, energy, physiological and anatomical levels in order to achieve a healthy state. Secondly, the acquisition of health saving skills to maintain a healthy state. Thirdly, the accumulation of experience of a healthy lifestyle with health saving skills in various domestic, social and natural seasonal conditions (spring, summer, autumn and winter) is necessary 
to maintain a healthy state throughout the year.

It is important for each person to form environmental health creative thinking. When a healthy lifestyle is established in a healthy society as a family and cultural tradition and passed on from generation to generation, then environmental health creative thinking gains synergy in the development of quality of life.

\section{Conclusion}

The effects of the coronavirus pandemic affected a number of global social and economic processes at once. Despite the fact that the whole world is actively fighting these consequences, as shown by the macroeconomic measures adopted - short-term problems are unlikely to be easily overcome. The fight against the crisis in this case can not so much eliminate, but delay the manifestation of a number of problems. While authorities and regulators in the US and Europe hope that they will gradually cope with the accumulated short-term imbalances over the coming years, some changes, including in value chains, world trade, the level of inequality between and within countries, are likely to remain with us for a long time and create new long-term challenges.

Synergistic international interaction between different forms of activity will help to cope with the problems encountered in various areas of public life. Synergistic international interaction has emerged in the field of health in the fight against the pandemic. If synergistic international interaction moves harmoniously into all spheres of human activity, then humanity will gradually solve pressing problems [15].

\section{References}

[1] Evgeniy Bryndin. International Harmonization of Human Life and Society. International Peer-Reviewed Journal on Humanities \& Social Science, Volume-6, Issue 11. 2020. 135137.

[2] Evgeny Bryndin. Synergistic Formation of Harmonious Socio and Uniform Economic Order. International Journal of Science, Technology and Society. Volume 9, Issue 1, 2021, pp. 14-22.

[3] Evgeniy Bryndin. Mission of universities in era of rapid technological development. Journal of Educational System Volume 4, Issue 1, 2020, PP 36-40.
[4] Evgeniy Bryndin. Diversified Transformation of University Inside and in Interaction with Industrial and Social Environment. Education Journal. Volume 9, Issue4, 2020. Pages: 95-98.

[5] Evgeny Bryndin. Aspects of Research Training and Commercialization Research Results. Science Journal of Education. Vol. 9, No. 1, 2021, pp. 6-13.

[6] Ivanova I., Strand Ø., Leydesdorff L. The Synergy and Cycle Values in Regional Innovation Systems: The Case of Norway. Foresight and STI Governance. 2019. Vol. 13. No. 1. P. 48-61.

[7] Landon Kleis, Barrie R. Nault, Albert S. Dexter. Producing Synergy: Innovation, IT, and Productivity. Decision Sciences 45 (5), 2014. DOI: 10.1111/deci.12093.

[8] Lee, Ryeowon, Lee, Jong-Ho, Garrett, Tony C. Synergy effects of innovation on firm performance. Journal of Business Research Volume 99, June 2019, Pages 507-515. URL: http://www.sciencedirect.com/science/article/pii/S0148296317 302916.

[9] Evgeny Bryndin. Economic Aspect of Global Wellbeing. Journal "The European Proceedings of Social \& Behavioural Sciences". Volume VII. 2016. Pages 14-21.

[10] Evgeniy Bryndin. Creation of Social Self-sufficient Digital Ecological Economy of Natural Needs of Healthy Living Activities. Resources and Environmental Economics, Vol. 2, Issue 2. 2020. pp. 184-190.

[11] Evgeniy Bryndin. Development of living floor spaces on the basis of ecological economic and social programs. J. Resources and Environmental Economics. V. 1, N. 1.2018. P. $1-8$.

[12] Bryndin E. G., Bryndina I. E. Natural Technology of High Quality Transition to Healthy Activity. J. Galore International Journal of Health Sciences and Research. Vol. 3; Issue: 1. 2018. P. 24-32.

[13] Bryndin E. G., Bryndina I. E. Hygiene and Endoecology, Light Bioenergy and Natural Ecology, Balanced Mentality and Spiritual Life as Criterion of Health. Innovative Journal of Medical and Health Science. Vol 9, Iss 2, 299-306. 2019.

[14] Evgeniy Bryndin, Irina Bryndina. Development of Health Care on Basis of Healthy Lifestyle for Forming Future Medicine of Longevity. Acta Scientific Medical Sciences, V3, №5 (2019): 35-41.

[15] Matteo Pedercini, Steve Arquitt, David Collste, and Hans Herren. Harvesting synergy from sustainable development goal interactions. PNAS November 12, 2019116 (46) 2302123028 URL: https://doi.org/10.1073/pnas.1817276116. 